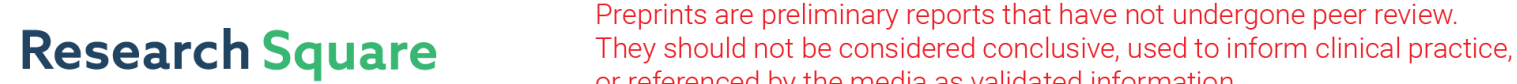 or referenced by the media as validated information. \\ Finite Element Based Thermal Model For Analyzing The Material Removal of Different Work Material In ECDM Process
}

Vivek Sharma ( $\square$ viveksharma.be18prod@pec.edu.in )

PEC: PEC University of Technology

\section{Research Article}

Keywords: Finite Element Analysis, MRR, ECDM, Heat Transfer, Non-Conducting Materials

Posted Date: February 12th, 2021

DOl: https://doi.org/10.21203/rs.3.rs-189920/v1

License: (c) (1) This work is licensed under a Creative Commons Attribution 4.0 International License.

Read Full License 


\title{
Finite element based thermal model for analyzing the material removal of different work material in ECDM process
}

\author{
Vivek Sharma email id = manjusharma76.ms@gmail.com \\ Affiliation $=$ Punjab Engineering College Chandigarh
}

\begin{abstract}
Electrochemical discharge machining (ECDM) is a novel technique for machining non-conductive materials like quartz, soda lime glass, ceramics etc. It combines the machining attributes of the electric discharge machining (EDM) and electrochemical machining (ECM) simultaneously in a single process. Despite numerous experimental studies, few studies are reported covering analytical aspects of the ECDM process. The present study focusses on the development of finite element based thermal model for analyzing the material removal of the different work materials. The model is validated by comparing it with existing literature and a comparison of the different models based on different heat input i.e., uniform distribution and Gaussian distribution is also performed. Results revealed that the material removal rate (MRR) predicted using Gaussian distribution exhibits fair agreement with the earlier reported results. Moreover, the comparative study on MRR is performed using gaussian heat distribution for soda lime glass and quartz material. It is observed that under similar machining conditions, MRR of soda lime glass is higher than the quartz material. The MRR of the both the work materials increases with the increase in electrolyte concentration due to increase in total heat input over the work material.
\end{abstract}

Keywords: Finite Element Analysis, MRR, ECDM, Heat Transfer, Non-Conducting Materials

\section{Introduction}

ECDM or Electrochemical Discharge Machining (ECDM) is a combination of Electro Discharge Machining (EDM) and Electrochemical Machining (ECM). It is also known as Electrochemical anode machining (ECAM), chemical spark machining (ECSM) or Spark assisted chemical machining (SACM) and is one of the non-conventional machining processes. The micromachining of non-conductive materials such as quartz, glass, etc. is strenuous to perform due to their brittleness. Quartz and glass are in high demand in the field of Micro-electromechanical systems, aviation and medicine owing to their unique properties. They have good resistance to chemicals, and have high transparency and hardness [1,2]. Alumina is a state-of-the-art material that exhibits high strength to weight ratio, hardness and corrosion resistance, etc. These materials are widely used in advanced engineering applications such as automotive brakes, piezoceramic sensors, aerospace and biomedical implants due to their excellent biocompatibility [3,4]. But these materials are really hard to process by conventional machining methods as their material properties are altered by the cutting forces, resulting in failure. 
Thus, Electrochemical Discharge Machining (ECDM) is used. This is a complex process that is particularly useful for machining electrically non-conducting materials. The process involves multiple parameters including tool-electrode material, the size and shape of the electrode, wettability characteristics of tool-electrode, feed rate, workpiece material, current, applied voltage, the type of electrolyte used, gap between tool-electrode and workpiece, distance between cathode and anode, anode material, etc.

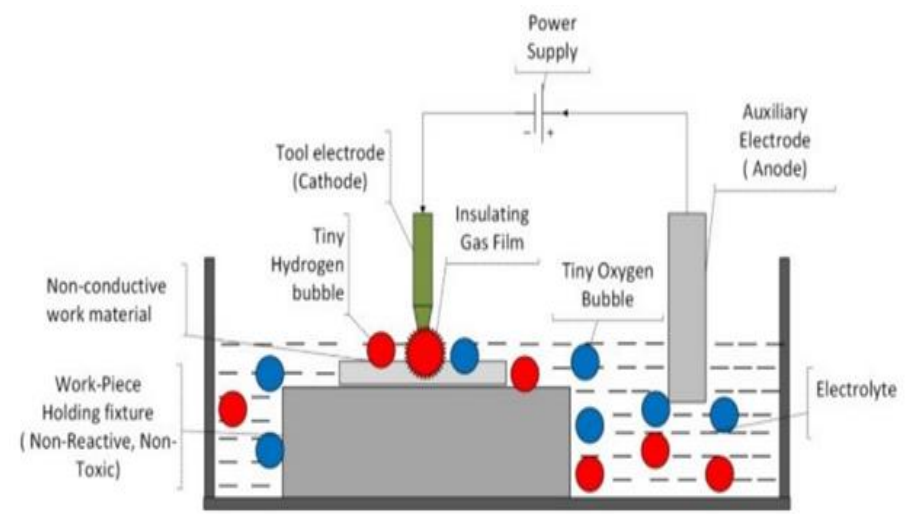

Figure 1: Schematic Diagram of Electrochemical Discharge Machining

Fig. 1 shows a schematic diagram of basic Electrochemical Discharge Machining process. In the process, the workpiece is dipped in a basic electrolyte such as $\mathrm{KOH}$ or $\mathrm{NaOH}$. A DC or pulse voltage is applied between the tool-electrode (usually cathode) and the counter electrode (normally anode). The polarity can also be reversed but doing so is not preferred as it has some disadvantages over direct polarity. The tool-electrode is dipped slightly (usually by a few millimeters) in the electrolyte. The counter electrode which is much larger in size (by a factor of about one hundred) is placed a few centimeters away from the tool-electrode. Electrolysis occurs at a voltage lower than critical voltage (typically between $20 \mathrm{~V}$ and $30 \mathrm{~V}$ ) and due to that, formation of hydrogen bubbles takes place at the tool-electrode and oxygen bubbles start forming at the counter-electrode As the terminal voltage increases, it causes an increase in the formation of gas bubbles and their mean radius, due to an increase in current density. This results in the formation of a layer of gas bubbles around the tool-electrode. Beyond a critical applied voltage, these bubbles fuse and form a gas film on the tool-electrode. This film acts as a dielectric and generates high resistance, which in turn creates a high potential difference between the electrodes. As the potential difference becomes high a given pair of tool-electrolyte system, electrical discharges do occur between the electrode and the electrolyte. If the workpiece is placed in the discharge zone, machining takes place in the form of melting, thermal erosion and vaporization due to the heat generated by discharges. Further, concurrent chemical etching also contributes to the machining operations. ECDM process can be used in creating micro holes, micro channels, and 3-D microstructures in non-conducting materials like ceramics or glass. 
Numerous authors and researchers have attempted to corelate different parameters to predict MRR using various tools such as FEA [5], Taguchi [6], response surface [7], fuzzy logic [8], and artificial neural network [9]. Every tool gives result by assuming some of the parameters. So, no theory has been completely generalized and widely accepted till now. (every tool gives result considering some of the assumptions and no theory is completely generalized and widely accepted till present.). Bhondwe Et Al. [10] conducted FEA two-dimensional thermal analysis, predicted MRR and compared the results with past experimental works to vindicate the mathematical model. Wei Et Al. [11] delivered the finite element model for discharge regime which is where most of the material removal takes place. Jain Et Al. [5] found the relationship between electrolyte concentration and thermal conductivity prosper, and then made a finite element model to show the same. Paul and Korah [12] did some simulations on the finite element model for pulsed spark for comparison between the MRR and maximum temperatures to get the result with that of a normal spark. Goud and Sharma [13] did finite element model by taking the calculation of the heat generation in 3-D Gaussian spark region and had a prediction of the MRR for Silica glass and alumina. The predictions were then compiled to compare the result achieved from the experiment and were found to be same. Nguyen et al. [14] investigated the effect of electrolyte level and feed rate on spark generation and spark stability while processing quartz and found out that low electrolyte levels increase heat energy as spark resistance reduces current. Jawalkar et al. [15] investigated the effect of various parameters they had on material removal rate while machining optical glass. Paul and Hiremath [16] tried to use mixed electrolyte and studied the effect the voltage and duty factor had on MRR and got to knew that micro-feature generation was very difficult with mixed electrolyte then it was with $\mathrm{NaOH}$ alone. Yadav [17] studied the wire ECDM process with FEM based thermal model. The predicted results from material removal were higher than the experimental results. It was because of an assumption of $100 \%$ ejection efficiency. Krotz et al. [18] studied the heat-affected zone (HAZ) in the ECDM process by simulation of a single spark in the two-dimensional thermal model. It was concluded that HAZ is equivalent to the diameter of the arc spot.

The aim of the present study is to develop a 3-D finite element thermal simulation with convective heat transfer taken into consideration for various materials and to perform a comparative analysis of the results with the already available results. ANSYS workbench transient thermal module shall be used to carry out the analysis as it makes use of mechanical APDL solver, the results given by which are largely accepted.

\section{Assumptions}

ECDM is a tangled process, so certain assumptions needed for simplification of Finite Element Modelling for MRR analysis of non-conducting materials [19-20].

1. Workpiece is assumed homogeneous and isotropic in nature.

2. Only one spark is assumed to take place under the tool tip at a single time. 
3. Heat generation within spark region assumed to be uniform and Gaussian distribution. The distribution of the heat remains constant for all the sparks.

4. Heat transfer due to radiation is ignored.

5. Material removal due to cavitations is neglected and the machining conditions remain uniform for single simulation.

\section{Methodology}

For the finite element analysis of different work materials, the transient thermal model is developed. Work material domain of size $0.6 \times 0.6 \times 0.4 \mathrm{~mm}^{3}$ is taken for MRR analysis. Soda lime glass and quartz work material is used for comparing the MRR. The critical physical and thermal properties used in FEM analysis is presented in table $1[10,13]$. $\mathrm{NaOH}$ is used as an electrolyte while a constant value of $45 \mathrm{~V}$ is used for performing all simulations.

Table 1 Critical properties of soda lime glass used in FEM.

\begin{tabular}{|c|c|c|}
\hline Property & Soda lime Glass & Quartz \\
\hline Thermal conductivity (W/mK) & 1.6 & 1.4 \\
\hline Heat Capacity $(\mathrm{J} / \mathrm{kgK})$ & 670 & 733 \\
\hline Melting Temperature (K) & 1673 & 1943 \\
\hline Room Temperature (K) & 298 & 298 \\
\hline Density $\left(\mathrm{kg} / \mathrm{m}^{3}\right)$ & 2100 & 2650 \\
\hline Convective Coefficient $\left(\mathrm{W} / \mathrm{m}^{2} \mathrm{k}\right)$ & 10000 & 10000 \\
\hline
\end{tabular}

Jain et al. [5] has utilized a uniform heat distribution over the work material for analyzing the ECDM process. On the contrary, many researchers have utilized the Gaussian distribution in a spark region for estimating the MRR of the ECDM process. Kulkarni et al. [21] found that a crater dimension of $300 \mu \mathrm{m}$ is formed during micro-machining process. So, Spark of diameter $300 \mu \mathrm{m}$ is used for FEM analysis. A constant spark duration of $100 \mu \mathrm{s}$ is assumed [22]. The transient temperature distribution within the workpiece is considered as axial-symmetric which is given by Equation 1

$$
k\left[\frac{1}{r}\left(r \frac{\partial T}{\partial r}\right)+\frac{\partial^{2} T}{\partial x}\right]=\rho c \frac{\partial T}{\partial t}
$$

where ' $\mathrm{k}$ ' assumes thermal conductivity, 'c' assumes specific heat capacity and ' $\rho$ ' assumes density of the workpiece material, respectively.

Heat input is assumed over a spark region which in the form of Gaussian function as given by Equation 2

$$
f(x, y)=\operatorname{Aexp}{ }^{-\left(\frac{\left(x-x_{0}\right)^{2}}{2 \sigma_{x}^{2}}+\frac{\left(y-y_{o}\right)^{2}}{2 \sigma_{y}^{2}}\right)}
$$


where 'A' assumes to be max amplitude and $\sigma_{x}, \sigma_{y}$ are the spread of the spark in $\mathrm{x}$ and $\mathrm{y}$ direction and assumed to be equal in this case. The Gaussian heat input $(\mathrm{H})$ used for FEM analysis over spark region is given in Equation 3 [10]

$$
H=\frac{4.45 E_{p} V_{c} I_{c}}{\text { Area of Spark }} \exp \left\{-4.5\left\{\left(\frac{r_{x}}{R}\right)^{2}+\left(\frac{r_{y}}{R}\right)^{2}\right\}\right\}
$$

where ' $\mathrm{V}$ ' is voltage, ' $\mathrm{I}$ ' is the current which is a function of electrolyte concentration, $\mathrm{r}_{\mathrm{x}}, \mathrm{r}_{\mathrm{y}}$ is the radial distance, $\mathrm{R}$ is the spark radius. Energy transference $\left(\mathrm{E}_{\mathrm{p}}\right)$ of $20 \%$ used for the analysis $[23,24]$. The uniform heat within the spark radius remains uniform and retains same value all over, while heat distribution using the Gaussian heat is maximum at the center of the spark and decreases along the radial direction. The graphical depiction of a two-dimensional Gaussian Equation is shown in Fig-2. The Z-axis here represents the heat flux in $\mathrm{W} / \mathrm{m}^{2}$. The current (I) for specific concentration (C) of electrolyte derived from the literature and given in Equation 4 [21,25].

$$
I=3.2323 * 10^{-5} C^{3}-0.0027056 C^{2}+0.091378 C+0.71429
$$

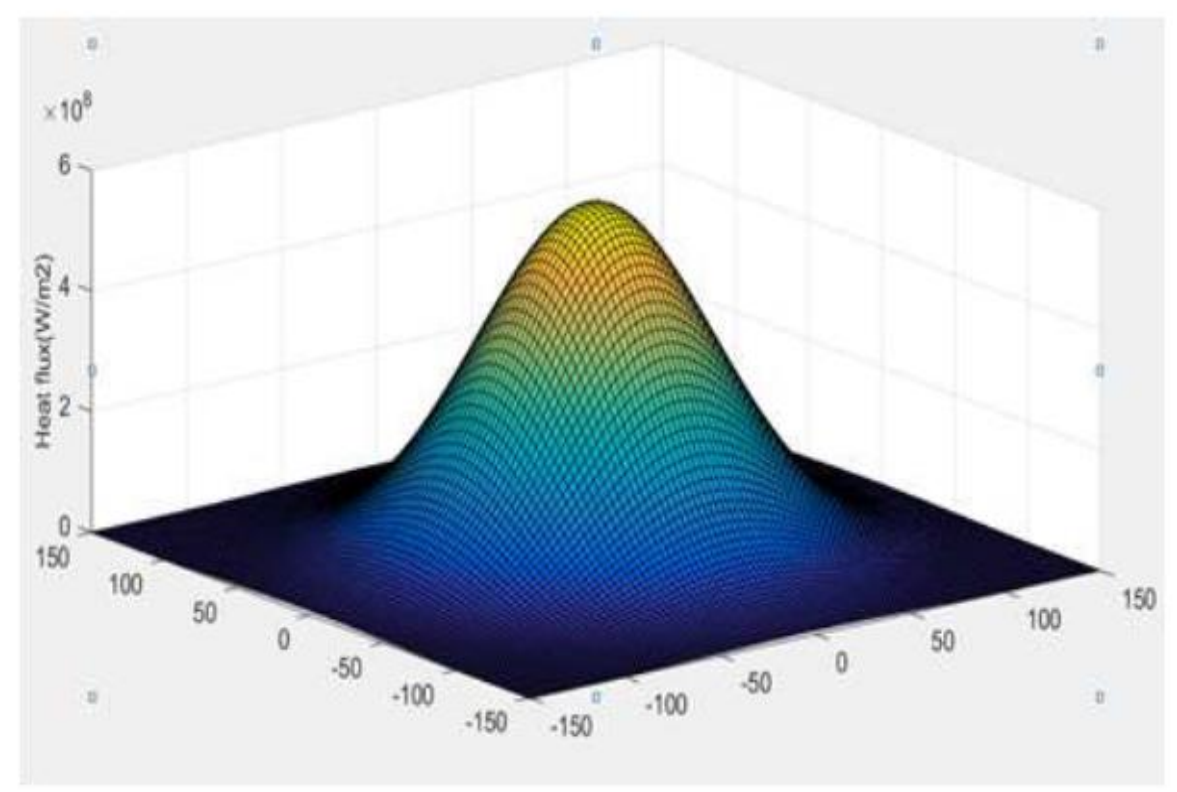

Figure 2 Gaussian distribution of Heat Flux [25]

\section{Boundary conditions}

1. At time $(\mathrm{t}=0)$ the work material is immersed in electrolyte and its temperature is assumed to be room temperature.

2. Heat Flux is applied over at the heat input boundary (AB) in a two different manner i.e, uniformly and Gaussian using Equation 3 as shown in Figure 3. 
3. All boundaries (A1, A2, A3, A4) are perfectly insulated. No heat transfer takes place through these boundaries.

$$
\frac{\partial T}{\partial n}=0, \mathrm{t} \geq 0
$$

4. The remaining top surface boundary $(\mathrm{BC})$ releases heat due to convection given by Equation 8. ' $h$ ' is the convective heat transfer coefficient.

$$
C=h\left(T-T_{0}\right)
$$

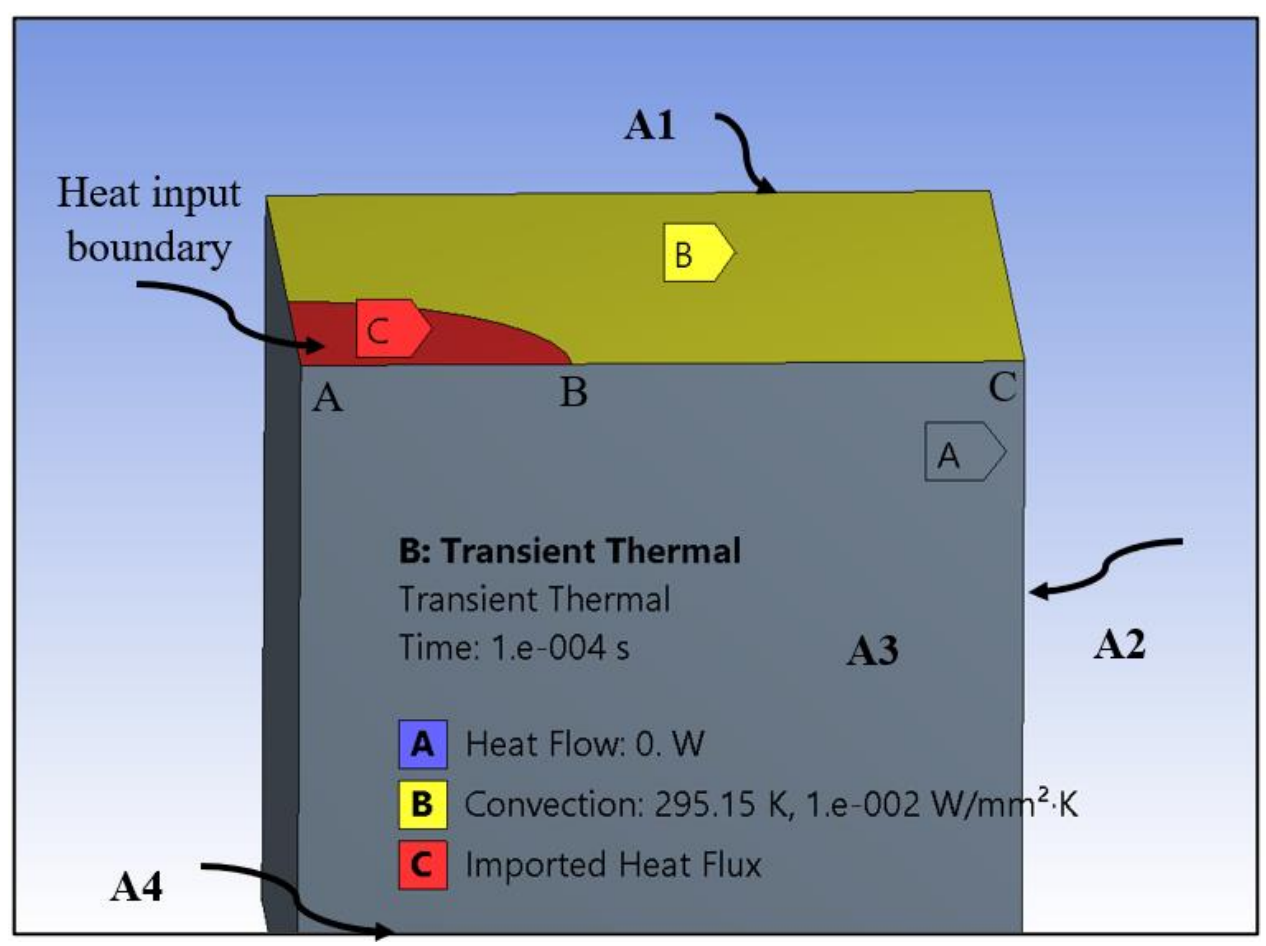

Figure 3: Model with boundary conditions

\section{Estimation of MRR}

ECDM is a process in which MRR is caused by thermal heating and sparks generation on the surface of materials. So MRR estimation is obtained by using isothermal planes of different material which is obtained from FEM results. The isothermal plots of the crater formed due to single spark are used at the melting temperature and further post processed to predict the MRR as shown in Figure 4. The work material temperature distributions obtained during simulation is shown in Figure 5. Different materials give different thermal plots that are further utilized for the comparison of MRR.

Material removal takes place only when thermal temperature of material becomes greater than material melting temperature as shown in Equation 7. As we know that material removal directly proportional to temperature.

$$
T>T_{m}
$$


As we know melting temperature $\left(\mathrm{T}_{\mathrm{m}}\right)$ for MRR estimation gives intercepts for calculation of volume of material removed $\left(\mathrm{V}_{\mathrm{m}}\right)$. These are $\mathrm{r}_{\mathrm{p}}$ and $\mathrm{z}_{\mathrm{p}}$ intercepts which is given in Equation 8 . The shape of the material removed is assumed to be hemisphere as shown in Figure 4. [23,24]

$$
V_{m}=\iiint r_{p} z_{p} \theta d r d z d \theta=\frac{2}{3} \pi r_{p}^{2} z_{p}
$$

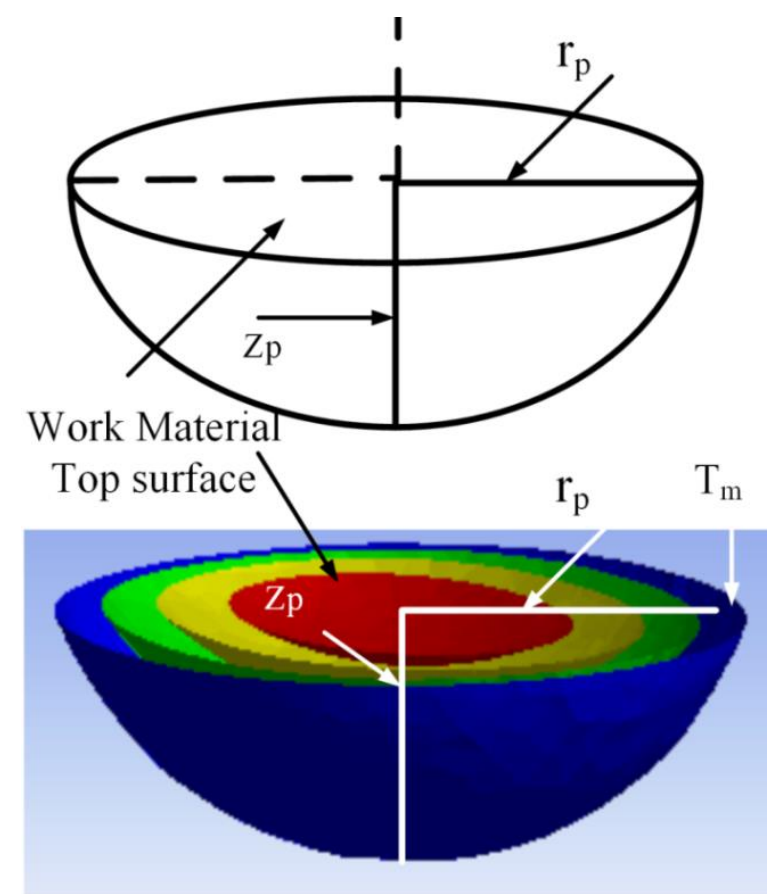

Figure 4: Isothermal Curve for MRR Estimation [20]

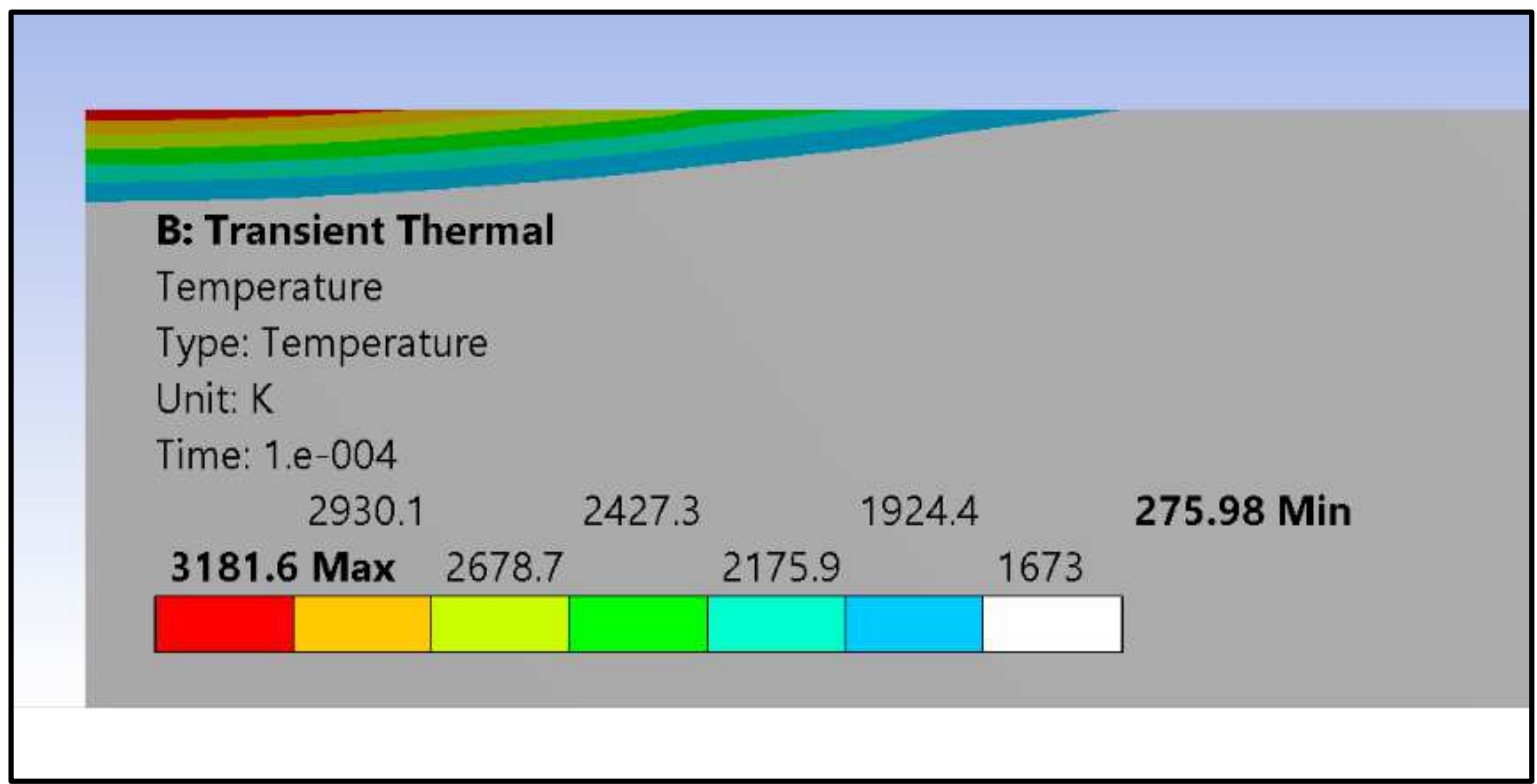

Figure 5 Temperature distribution within the work material with Gaussian distribution at 15 wt. $\%$ and $45 \mathrm{~V}$. 
The total volume $\left(\mathrm{V}_{\mathrm{T}}\right)$ in a unit time is calculated by multiplying the volume removed due to single spark with total number of sparks in a unit time, expressed in Equation 9.

$$
V_{T}=V_{m} X \text { number of sparks per unit time }
$$

Now, Final MRR is predicted using Equation 10, which multiply the total volume removed with density of material.

\section{Results and Discussion}

$$
M R R=V_{T} X \rho
$$

\subsection{Model validations}

The developed FEM based thermal model is validated by comparing it with the previous reported FEM results as well as experimental results. The model is meshed using tetrahedron method for improving the accuracy of the solver as shown in Figure 6. The comparison of MRR is performed for both the heat distributions i.e., uniform and Gaussian. Figure 7 shows the comparison of precited MRR at different electrolyte concentrations. It is observed that the trend of MRR variation exhibits similarity with the previously reported MRR. However, some differences exist in the value of MRR that may be seen due to the different method of applying heat input to the work material. A difference among the present simulation and previous experimental studies is observed because of different assumptions made during the study. It is noted that the calculation of energy fraction during experimental study is very difficult. Hence, may result in the minor variation in the predicted MRR.

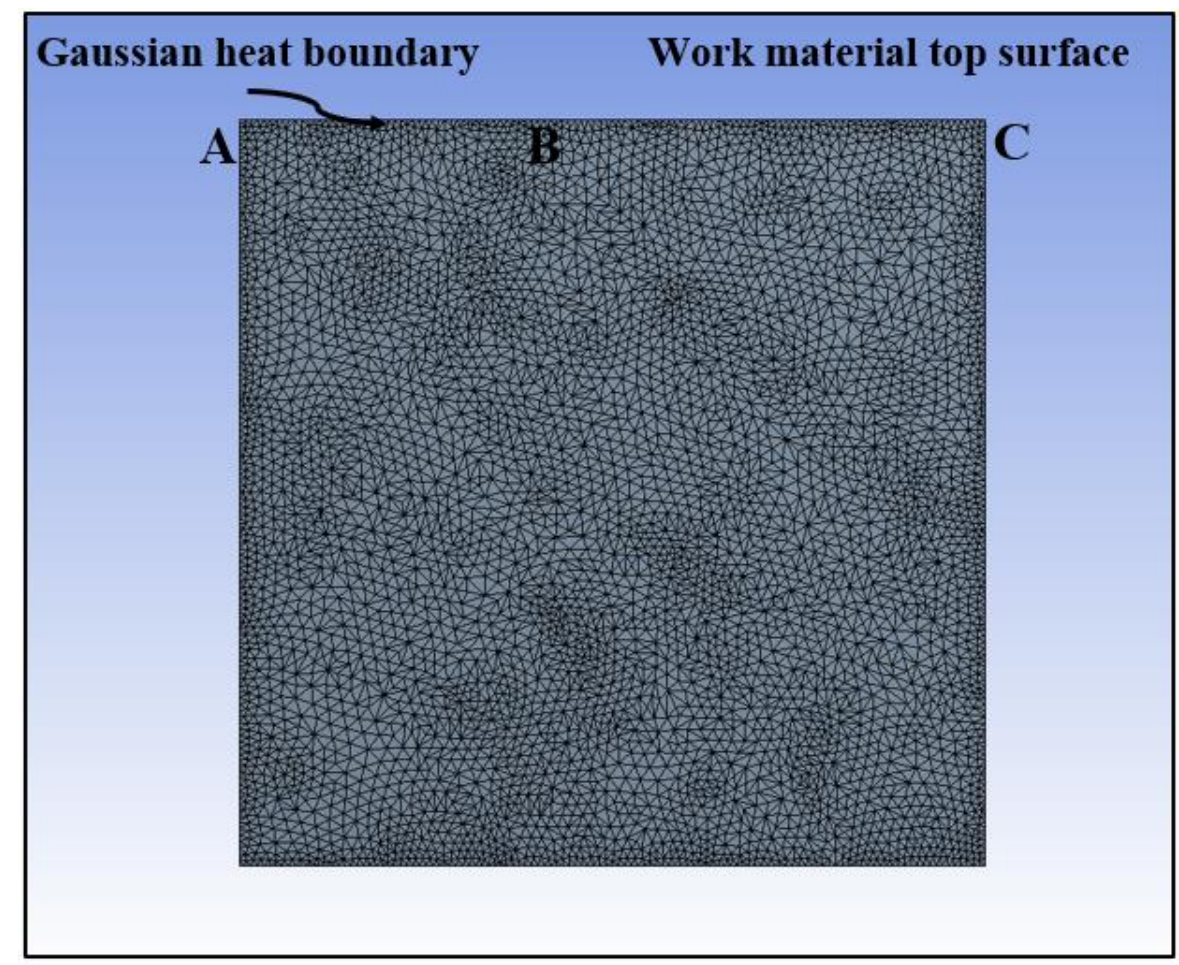

Figure 6 Meshed thermal model (Front view) 
Moreover, it is observed that MRR increases with the increase in electrolyte concentrations during simulation results. It is due to the fact that an increase in electrolyte concentrations increases the heat input over the work material that further results in an increase in work material temperature as shown in Figure 8. As a result, an increase in MRR is obtained. An increase in electrolyte concentration also leads to the enhanced rate of the electrolysis that further causes an increase in the generation of hydrogen bubbles. It results into the higher intensity of the sparks over the work material. Hence, an increase in MRR is seen during experimental studies.

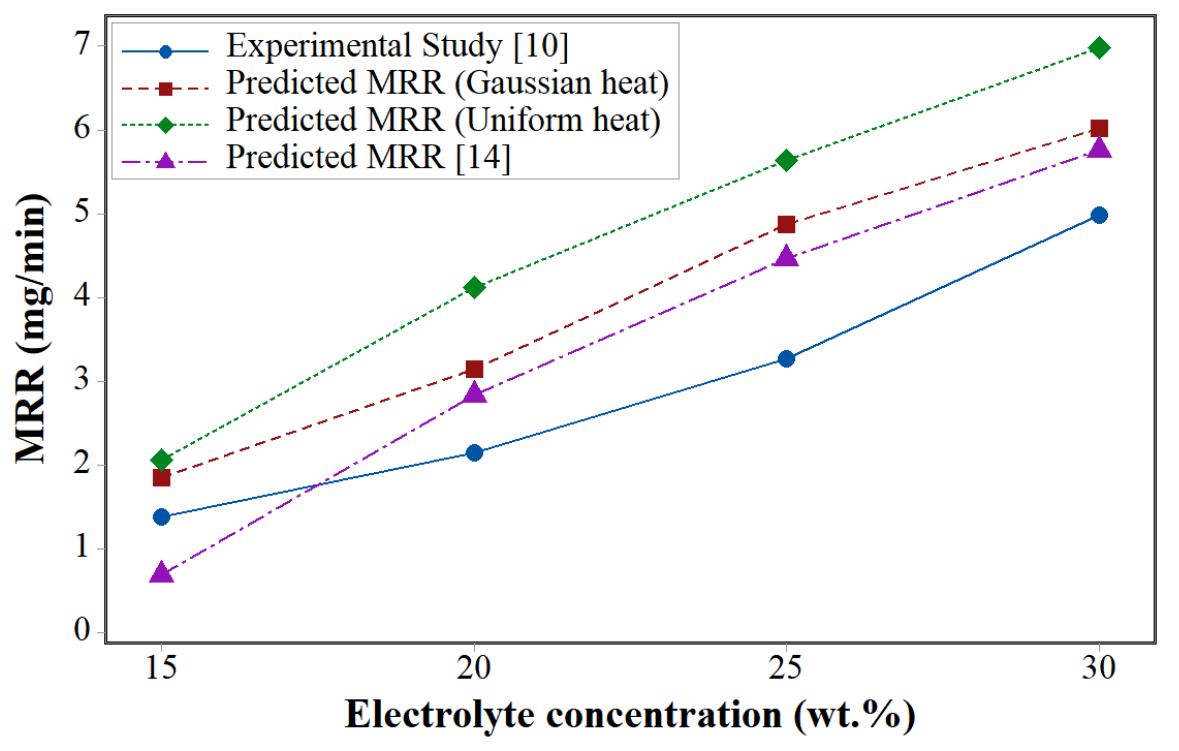

Figure 7 Comparison of MRR at different electrolyte concentration at $45 \mathrm{~V}$. 


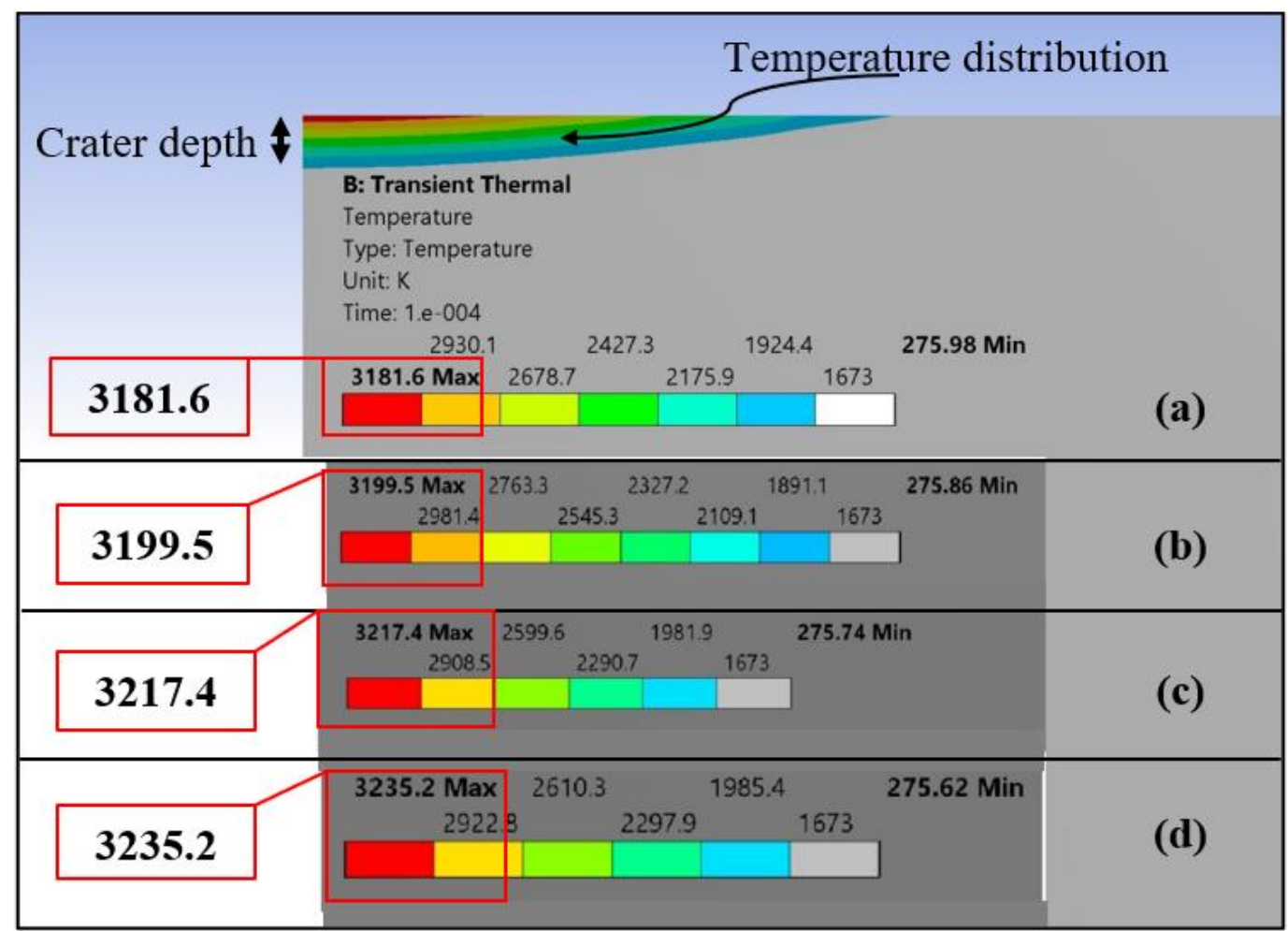

Figure 8 Work material temperature at different electrolyte concentration (a) 15 wt.\% (b) 20 wt.\% (c) 25 wt.\% (d) 30 $w t . \%$.

\subsection{Comparison of uniform heat and Gaussian heat}

The heat input to the work material is applied in a two different manner in terms of uniform heat and Gaussian heat as shown in Figure 9. The uniform heat distribution remains constant up to the spark radius while the heat input in Gaussian remains maximum at the center and decreases in a radial direction. Based on the MRR comparison (Fig.7), it is observed that MRR predicted using Gaussian heat input exhibits more closeness with the previously reported experimental and simulation studies when compared with the MRR predicted using uniform heat. Uniform distribution of the heat results in higher MRR when compared to the Gaussian heat distribution. The shape of the crater formed with uniform heat distribution is not hemispherical as reported by Kulkarni et al [21] during micro-machining when compared to the crater shape formed with Gaussian heat distribution as shown in Figure 10. It is explained due to the reason that Gaussian heat distribution demonstrates the true nature of the spark mechanism in ECDM process. 


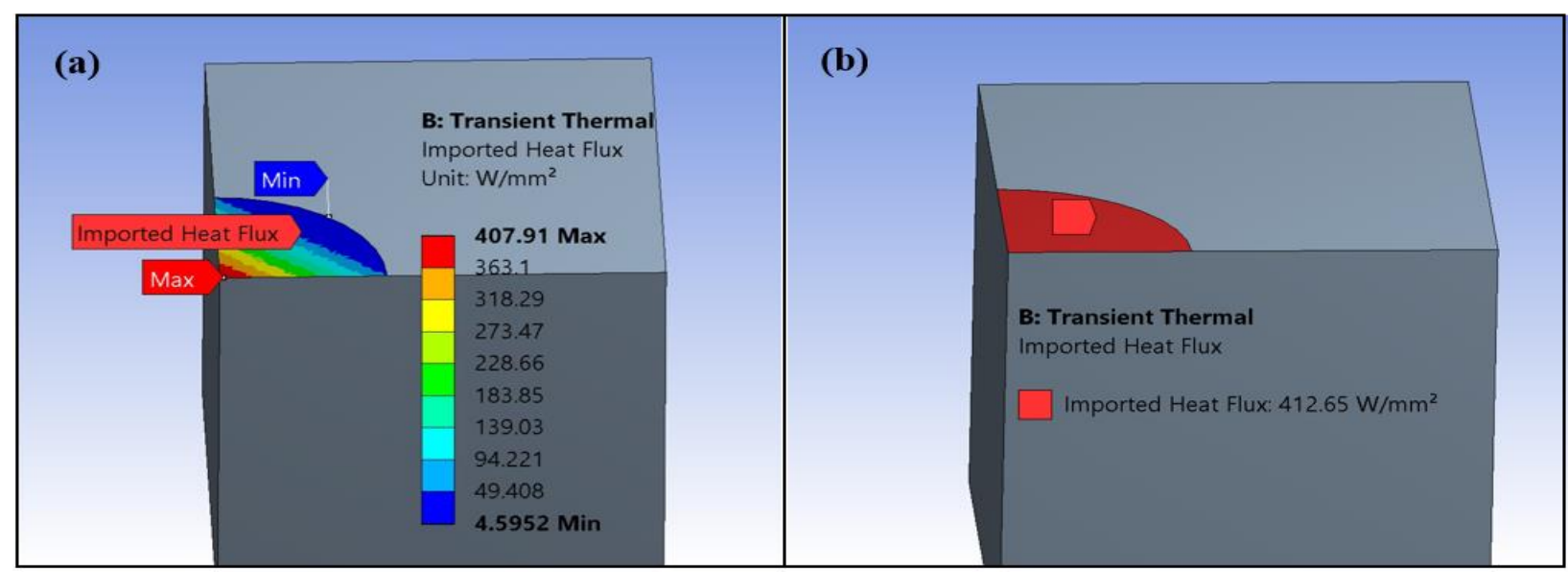

Figure 9 Heat input (a) Gaussian distribution (b) Uniform distribution.

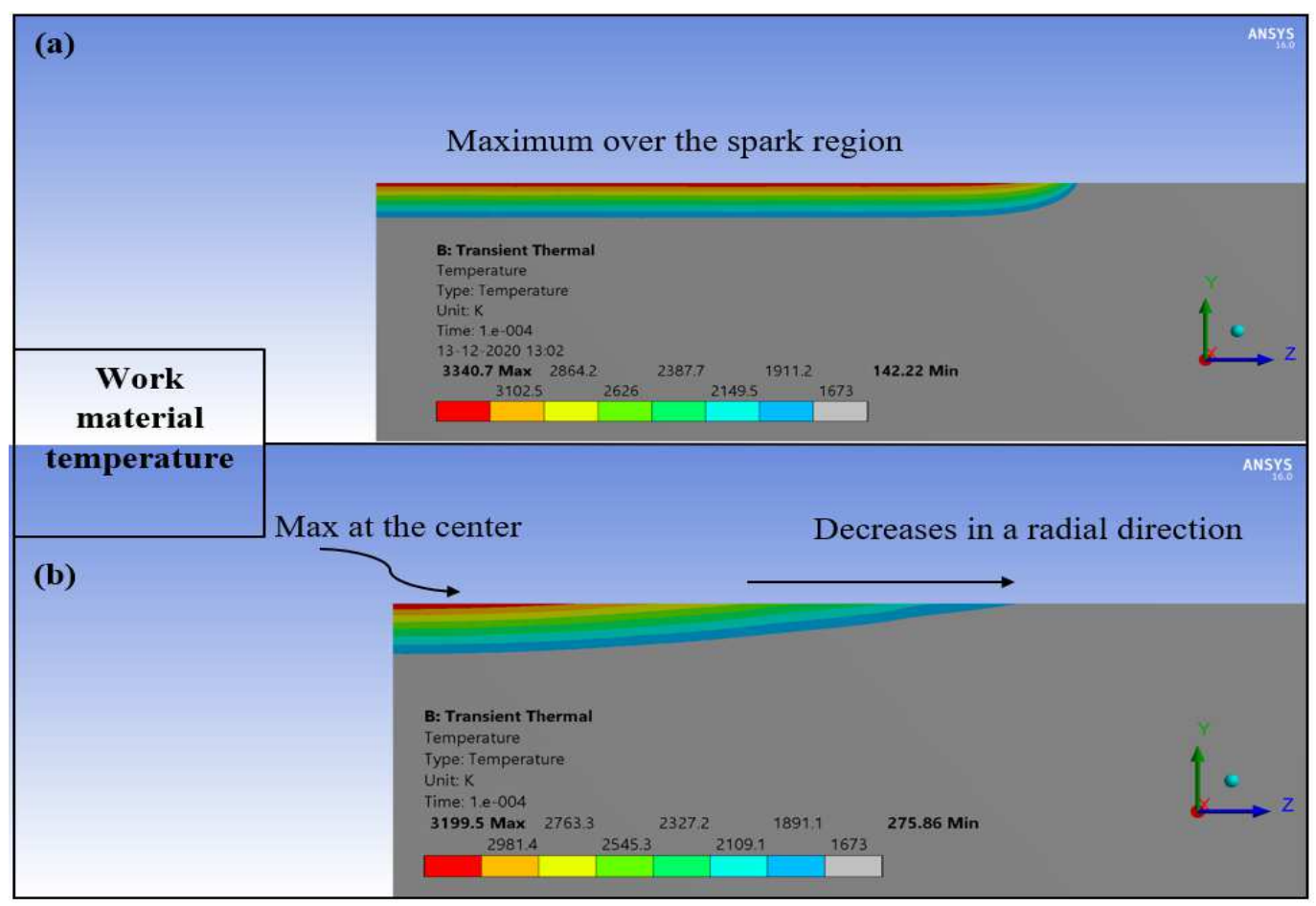

Figure 10 Crater shape (a) Uniform distribution (b) Gaussian distribution at 15 wt.\% NaOH and $45 \mathrm{~V}$.

\subsection{Comparison of soda lime glass and quartz work material}

Figure 11 shows the comparison of predicted MRR for soda lime glass and quartz work material at different electrolyte concentration. the comparison of MRR is carried out using Gaussian heat input since it exhibits more closeness to the previously reported results. The MRR of soda lime glass is higher when compared to quartz and increases with the increase in electrolyte concentrations (Fig. 7) as discussed in 6.1. Under similar working conditions, the work material temperature obtained within the soda lime glass material is higher than the work material temperature obtained within the Quartz material as shown in Figure 12. Also, the melting temperature of the Quartz work material is higher than the soda lime glass that causes less material to remove under similar working conditions. An increase of $5.46 \mathrm{mg}$ is observed in soda 
lime glass with the increase of electrolyte concentration from 15 wt.\% to 30 wt.\% when compared to an increase of $2.69 \mathrm{mg}$ in quartz under same conditions.

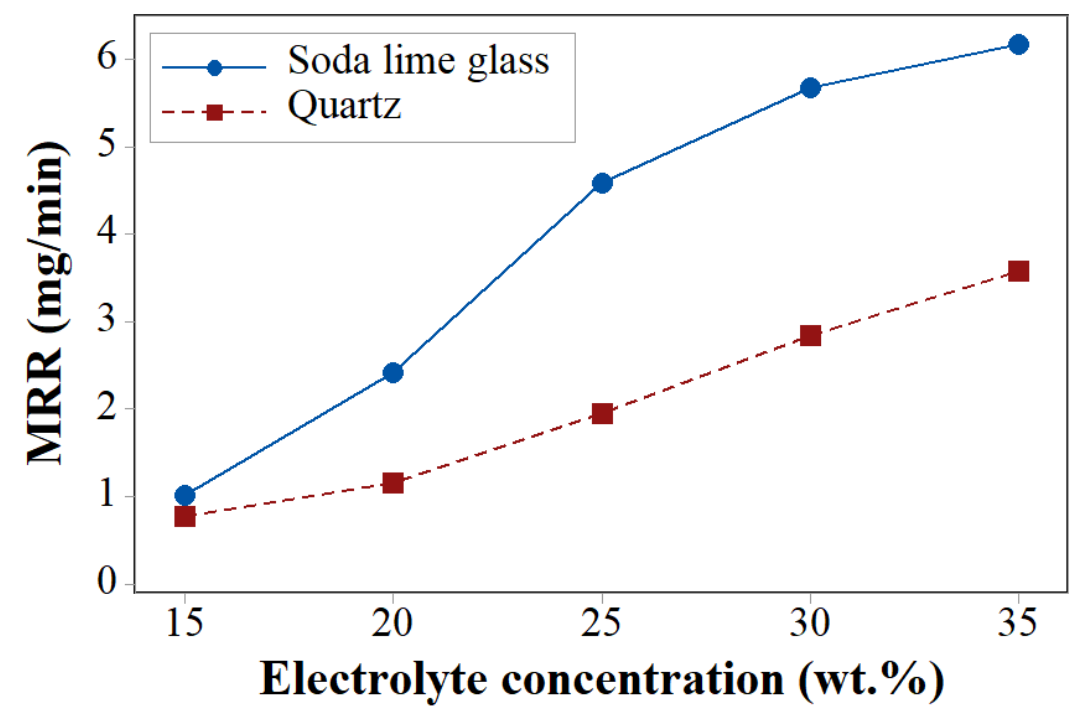

Figure 11 MRR comparison of different work materials at $45 \mathrm{~V}$.

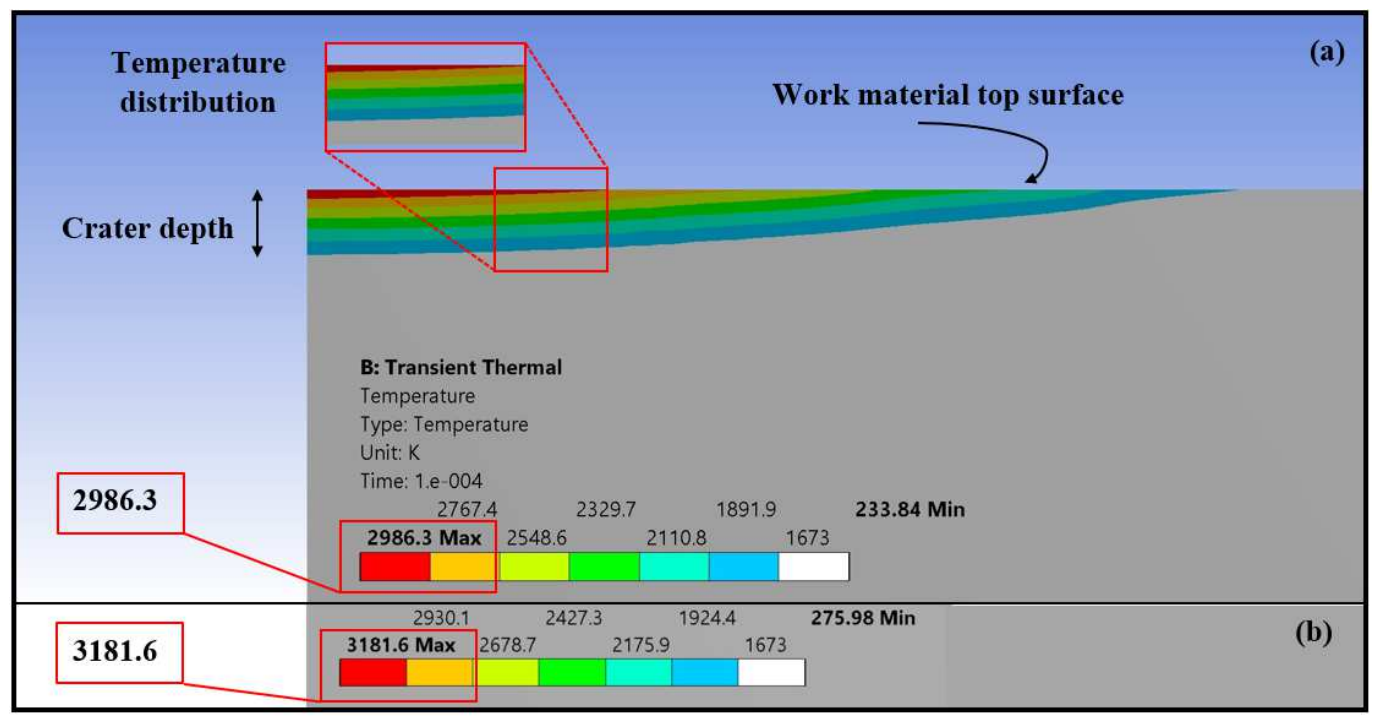

Figure 12 Work material temperature at 15 wt.\% and 45 V (a) Quartz (b) Soda lime glass.

\section{Conclusion}

Finite element based thermal model is developed to analyze the ECDM process using uniform heat distribution and Gaussian heat distribution. The predicted MRR is compared with the previously reported simulation and experimental study for validation. The results are also compared for analyzing the heat input. Additionally, a comparison of MRR for different work material is carried out. Based on present investigation, following conclusions are withdrawn:

- The developed thermal model illustrates a fair similarity with the existing results of FEM and experimental study. A slight difference in the MRR results is seen because of different assumptions made and use of different method of applying the heat input. 
- The trend of MRR is similar when compared to previously reported results that confirmed the model validity.

- MRR predicted through Gaussian heat input exhibits more closeness with the experimental results when compared with the uniform heat input. Gaussian heat input reveals true results in ECDM simulations.

- An increase in MRR is observed due to increase in electrolyte concentrations since it results in the increase in work material temperature.

- Soda lime glass is easier to remove as compared to Quartz work material because melting temperature of quartz is higher than the soda lime glass. Simulation results show that predicted MRR for soda lime glass is higher than the predicted MRR of quartz glass. Soda lime exhibits an increase of $5.46 \mathrm{mg}$ compared to $2.69 \mathrm{mg}$ increase in quartz under same machining conditions.

\section{Ethical Approval}

I give full approval for this .

\section{Consent To Participate}

I give full Consent to participate

\section{Consent To Publish}

I give full consent to Publish this paper

\section{Authors Contributions}

Vivek Sharma Corresponding author and main author is the main contribution in this.

That is me

\section{Funding}

Not Applicable

\section{Competing Interests}

I am full capable to compete with other people

\section{Availability of data}

All data and Pictures that I have publish that I truly my results.

\section{References}


1. Sindhu, D., Thakur, L., Chandna, P., (2019). Multiobjective Optimization of Rotary Ultrasonic Machining Parameters for Quartz Glass Using Taguchi-Grey Relational Analysis (GRA). Silicon, 11, 2033-2044, doi: 10.1007/s12633-018-0019-6.

2. Bindu Madhavi, J., Hiremath, S.S. (2019). Machining and Characterization of Channels and Textures on Quartz Glass Using $\mu$-ECDM Process. Silicon, 11, 2919-2931. doi: 10.1007/s12633019-0083-6.

3. Dam, H., Quist, P., Schreiber, M.P., (1995). Productivity surface quality \& tolerances in ultrasonic machining of ceramics. Journal of Material Processing Technology, 51, 358-368.

4. Zhang, J. H., Lee, T. C., Lau W. S., (1997). Study on the electro-discharge machining of a hotpressed aluminum oxide-based ceramic. J. Mater. Process. Technol., 63, 908-912.

5. V.K. Jain, P.M. Dixit, P.M. Pandey. On the analysis of the electrochemical spark machining process. International Journal of Machine Tools \& Manufacture 39 (1999) 165- 186.

6. Mitra NS, Doloi B, Bhattacharyya B. Analysis of Traveling Wire Electrochemical Discharge Machining of Hylam based Composites by Taguchi Method. International Journal of Research in Engineering \& Technology 2014; 2(2): 223-36.

7. Paul L, Hiremath SS. Response Surface Modelling of Micro Holes in Electrochemical Discharge Machining Process. Procedia Engineering 2013; 64: 1395-404.

8. Skraalak G, Skrabalak MZ, Ruszaj A. Building of rules base for fuzzy-logic control of the ECDM process. J Mater Process Tech 2004; 149(1-3): 530-5.

9. Sathisha N, Somashekhar S. Hiremath and Shivakumar J. prediction of material removal rate using regression analysis and artificial neural network of ecdm process, International Journal of Recent advances in Mechanical Engineering (IJMECH) May 2014; Vol.3, No.2

10. Bhonwe KL, Yadava V and Kathiresan G. Finite element prediction of material removal rate due to electrochemical spark machining. Int J Mach Tool Manuf 2006; 46: 1699-1706.

11. Chenjun Wei \& Kaizhou Xu \& Jun Ni \& Adam John Brzezinski \& Dejin Hu. A finite element based model for electrochemical discharge machining in discharge regime Int J Adv Manuf Technol (2011) 54:987-995

12. Lijo Paul, Libin V Korah Effect of Power Source in ECDM Process with FEM Modeling. Procedia Technology 25 (2016) $1175-1181$

13. Goud M, Sharma A.K. A three-dimensional finite element simulation approach to analyze material removal in electrochemical discharge machining. Proceedings of the Institution of 
Mechanical Engineers, Part C: Journal of Mechanical Engineering Science 2016, 0954406216636167.

14. Nguyen KH, Lee PA, Kim BH. Experimental Investigation of ECDM for Fabricating Microstructures of Quartz. Int J Precis Eng Man 2015; 16 (1): 5-12.

15. Jawalkar CS, Kumar P, Sharma AK. Parametric study while micro channeling on optical glass using microcontroller driven ECDM process. Advanced Materials Research Vol. 585 (2012) pp $417-421$

16. Lijo P, Hiremath SS. Characterisation of Micro Channels in Electrochemical Discharge Machining Process. Appl. Mech Mater 2014; 490-491: 238-42.

17. Panda, M. C. and Yadava, V. (2009). Finite element prediction of material removal rate due to traveling wire electrochemical spark machining. Int. J. Adv. Manuf. Technol., 45, 506-520

18. Krotz, H., Raoul, R. R. and Wegener, K. (2013). Experimental investigation and simulation of heat flux into metallic surfaces due to single discharges in micro-electrochemical arc machining micro-ECAM. Int. J. Adv. Manuf. Technol., 68, 1267-1275. doi: 10.1007/s00170-013-4918-9

19. Ranganayakulu, J., Somashekhar, S.H. and Lijo, P. Parametric analysis and a soft computing approach on material removal rate in electrochemical discharge machining, International Journal of Manufacturing Technology and Management 2011;24:23-39.

20. Fascio, V., Wuthrich, R., Viquerat, D. and Langen, H. 3D Micro structuring of Glass Using Electrochemical Discharge Machining (ECDM). Proc. Of the International Symposium of Micromechatronics and Human Science, Nagoya 1999;179-183.

21. A. Kulkarni, R. Sharan, G.K. Lal. An experimental study of discharge mechanism in electrochemical discharge machining. International Journal of Machine Tools and Manufacture 2002;42:1121-1127.

22 Sathisha N, Somashekhar S. Hiremath and Shivakumar J. prediction of material removal rate using regression analysis and artificial neural network of ecdm process, International Journal of Recent advances in Mechanical Engineering (IJMECH) May 2014; Vol.3, No.2

23 Saranya, S., Sankar, A.R. , (2015). Effect of tool shape and tool feed rate on the machined profile of a quartz substrate using an electrochemical discharge machining process, 2nd International Symposium on Physics and Technology of Sensors, ISPTS, pp. 313-316. 
24. Rajput, V.S., Goud, M.M., Suri, N. M., (2019). Experimental investigation to improve the removal rate of material in ECDM process by utilizing different tool electrode shapes, Int. J. Technical Innovation in Modern Engineering \& Science (IJTIMES), 5(2), 333-341.

25 Singh, D., Goud, M.M. (2018). A 3D spark model to evaluate MRR in ECDM. Journal of Advanced Manufacturing Systems, 18(3), 435-446. doi: 10.1142/S0219686719500239. 


\section{Figures}

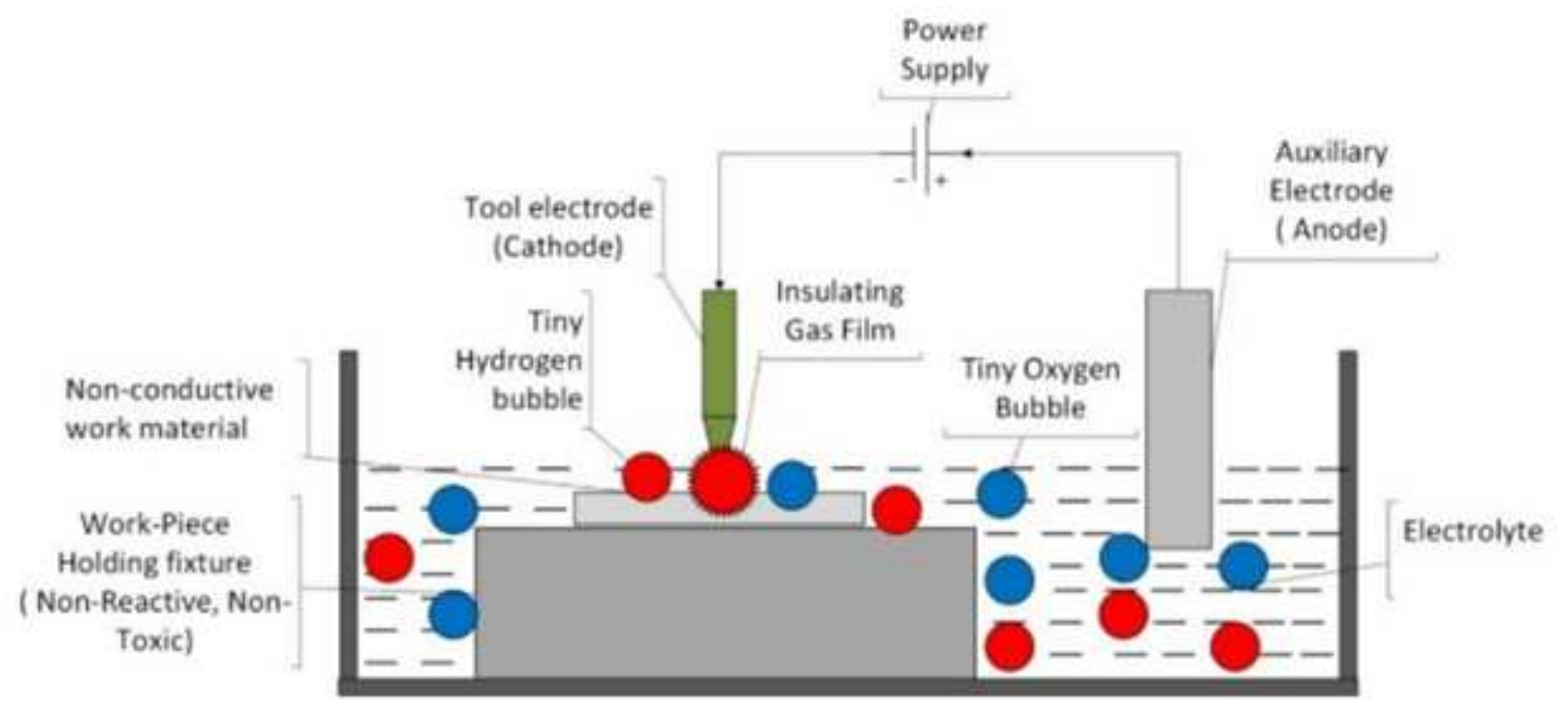

\section{Figure 1}

Schematic Diagram of Electrochemical Discharge Machining

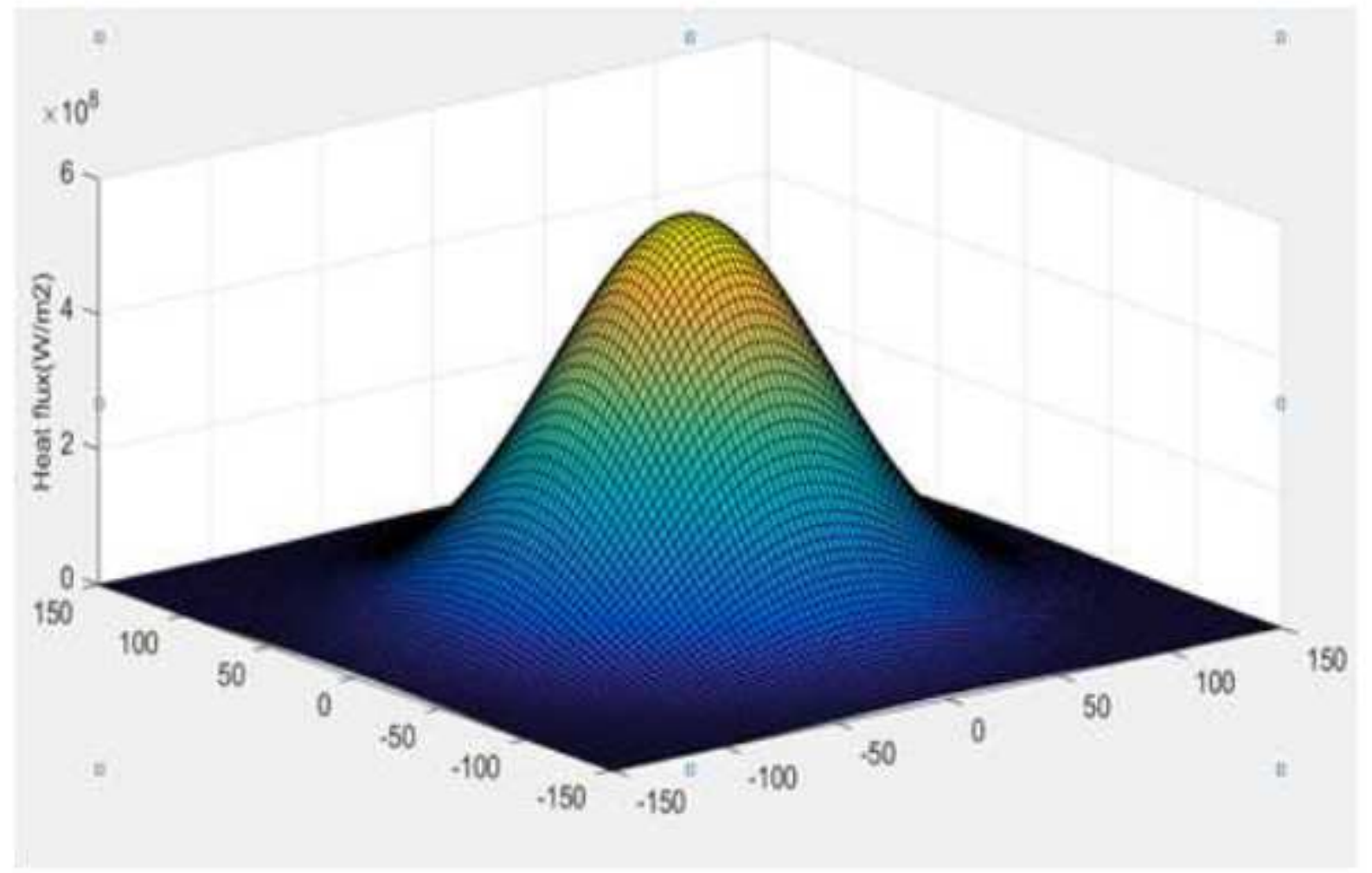

Figure 2

Gaussian distribution of Heat Flux [25] 


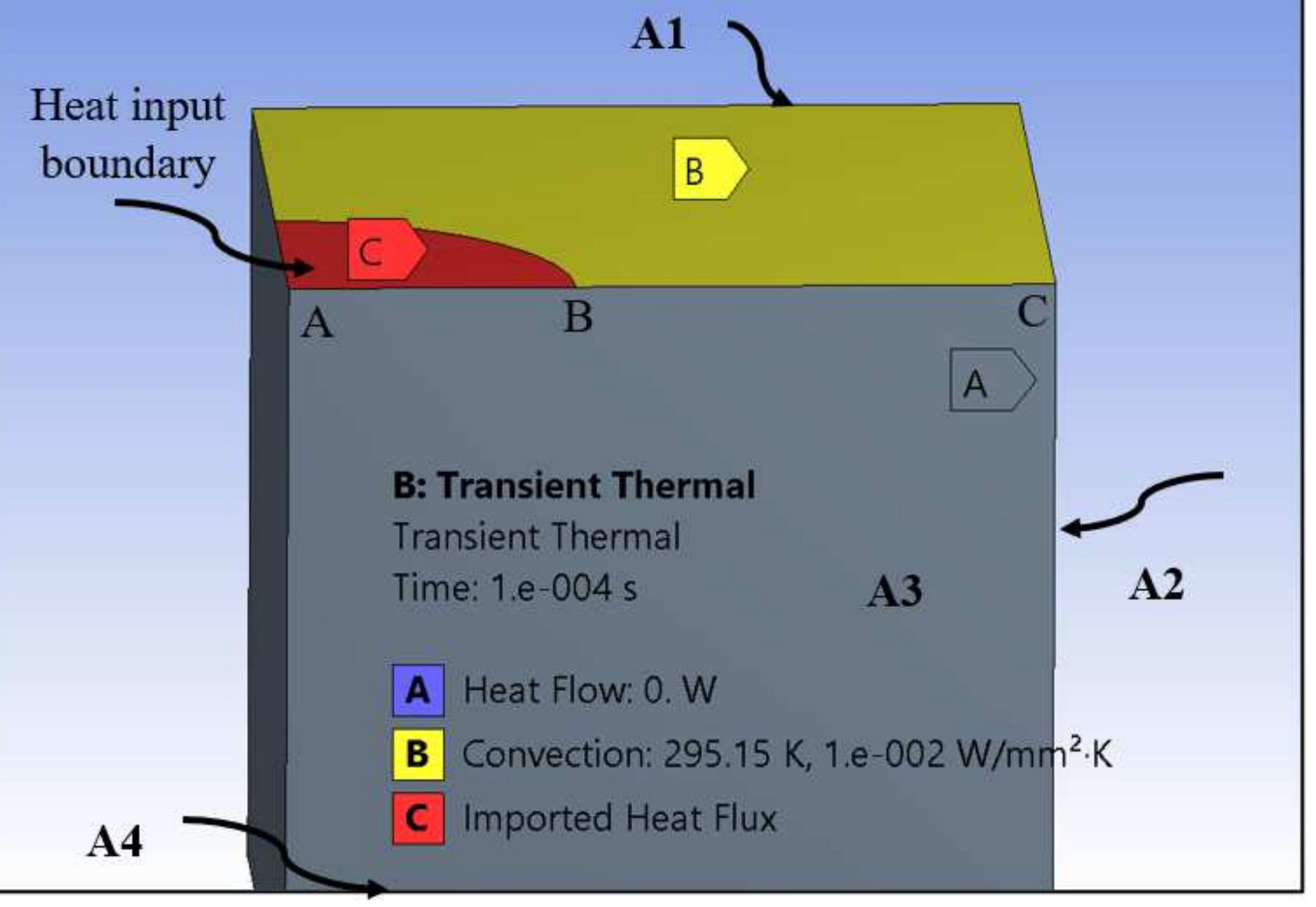

Figure 3

Model with boundary conditions 


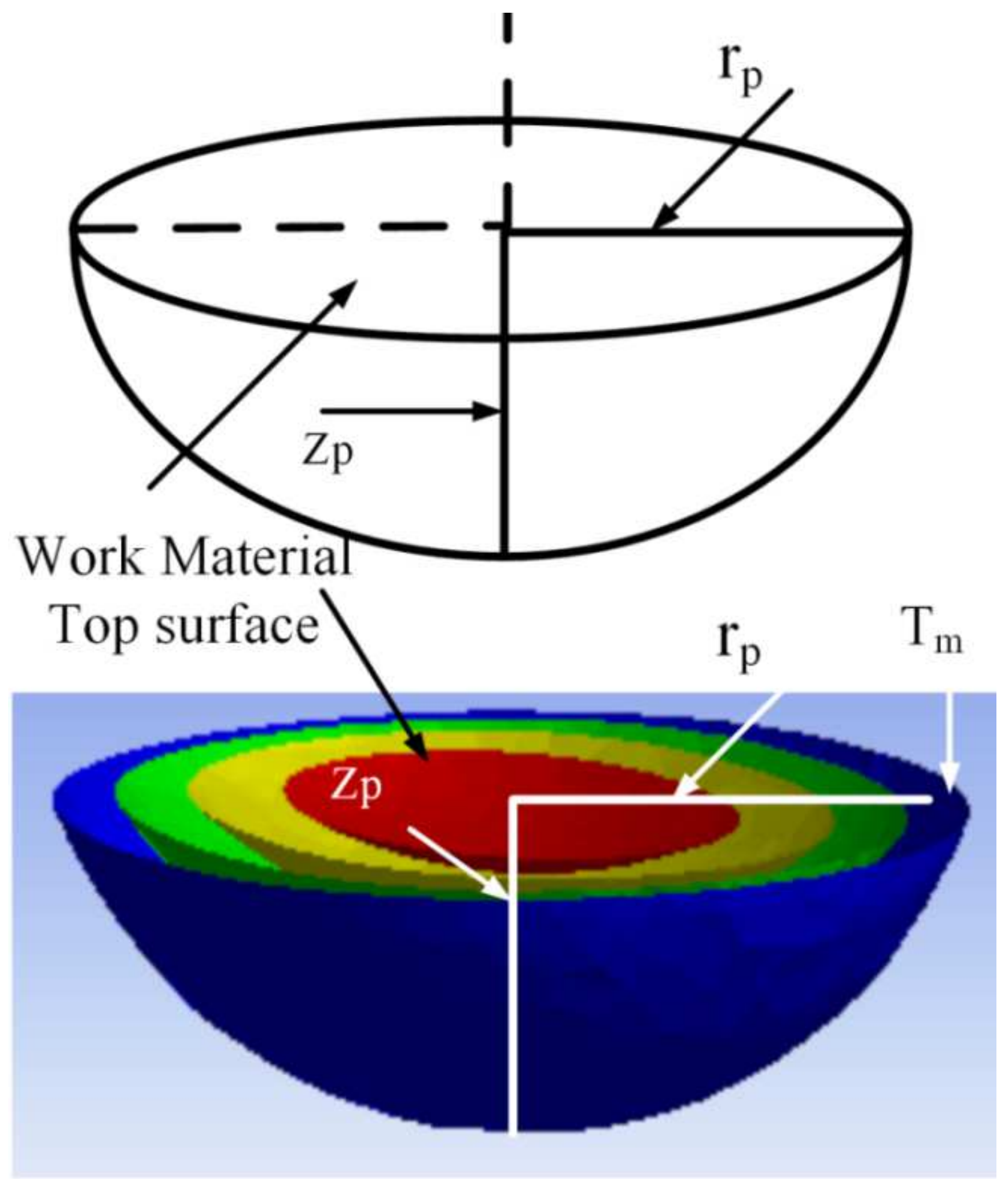

Figure 4

Isothermal Curve for MRR Estimation [20] 


\section{B: Transient Thermal}

\section{Temperature}

Type: Temperature

Unit: $K$

Time: $1 . e-004$

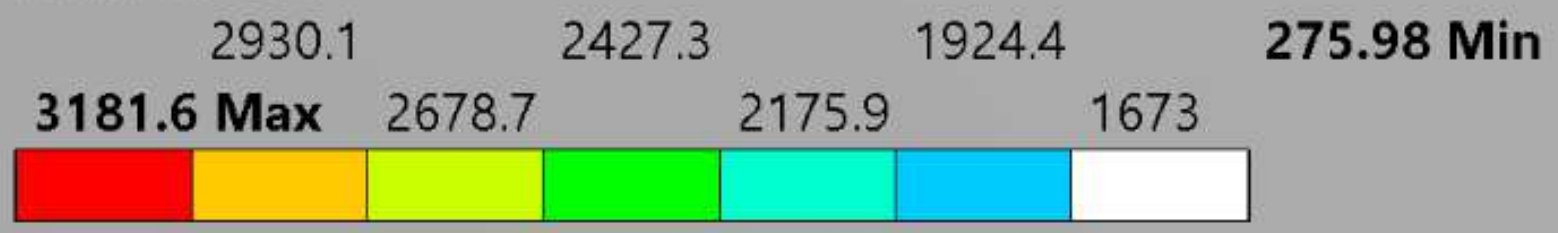

\section{Figure 5}

Temperature distribution within the work material with Gaussian distribution at 15 wt.\% and $45 \mathrm{~V}$. 


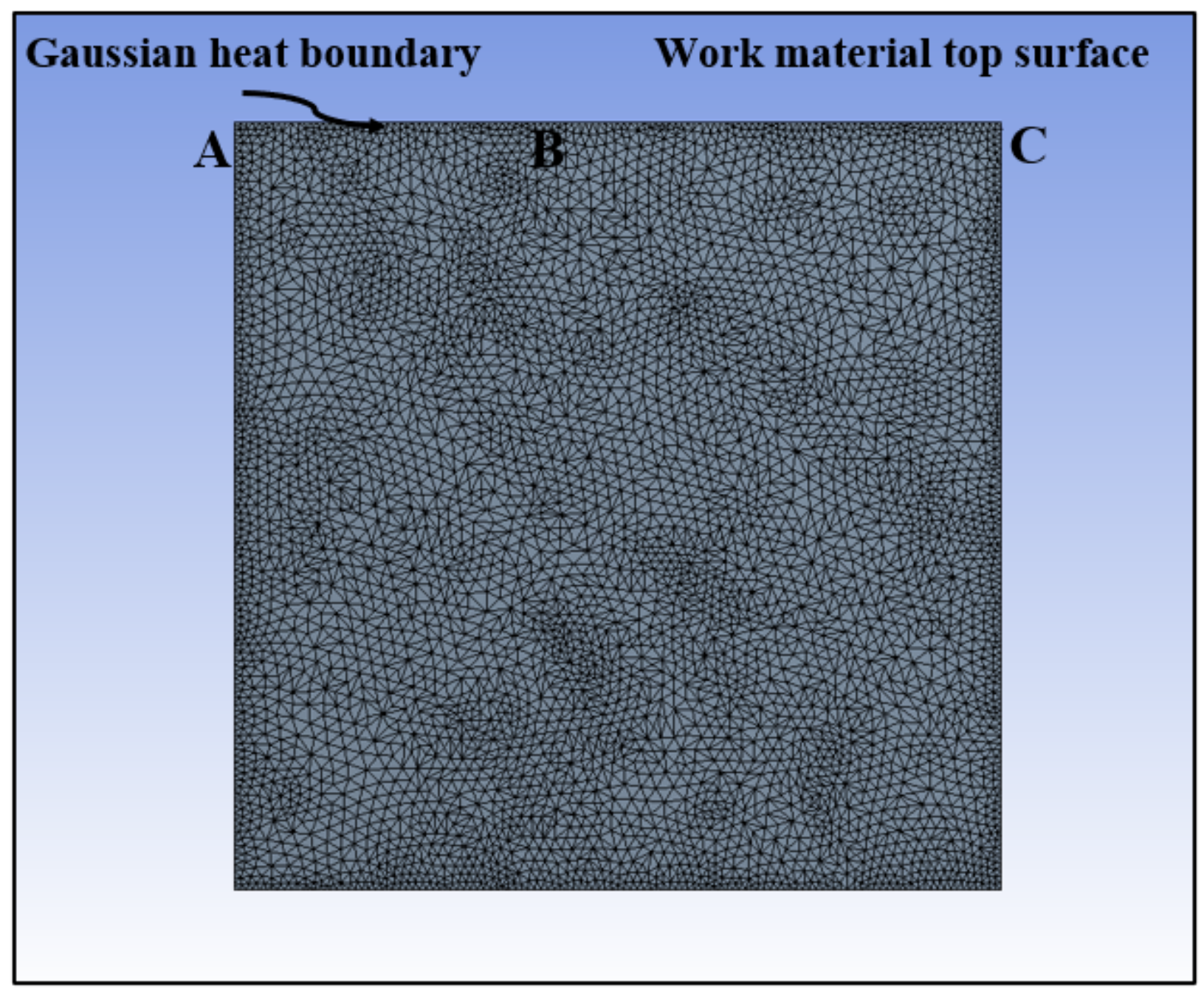

Figure 6

Meshed thermal model (Front view) 


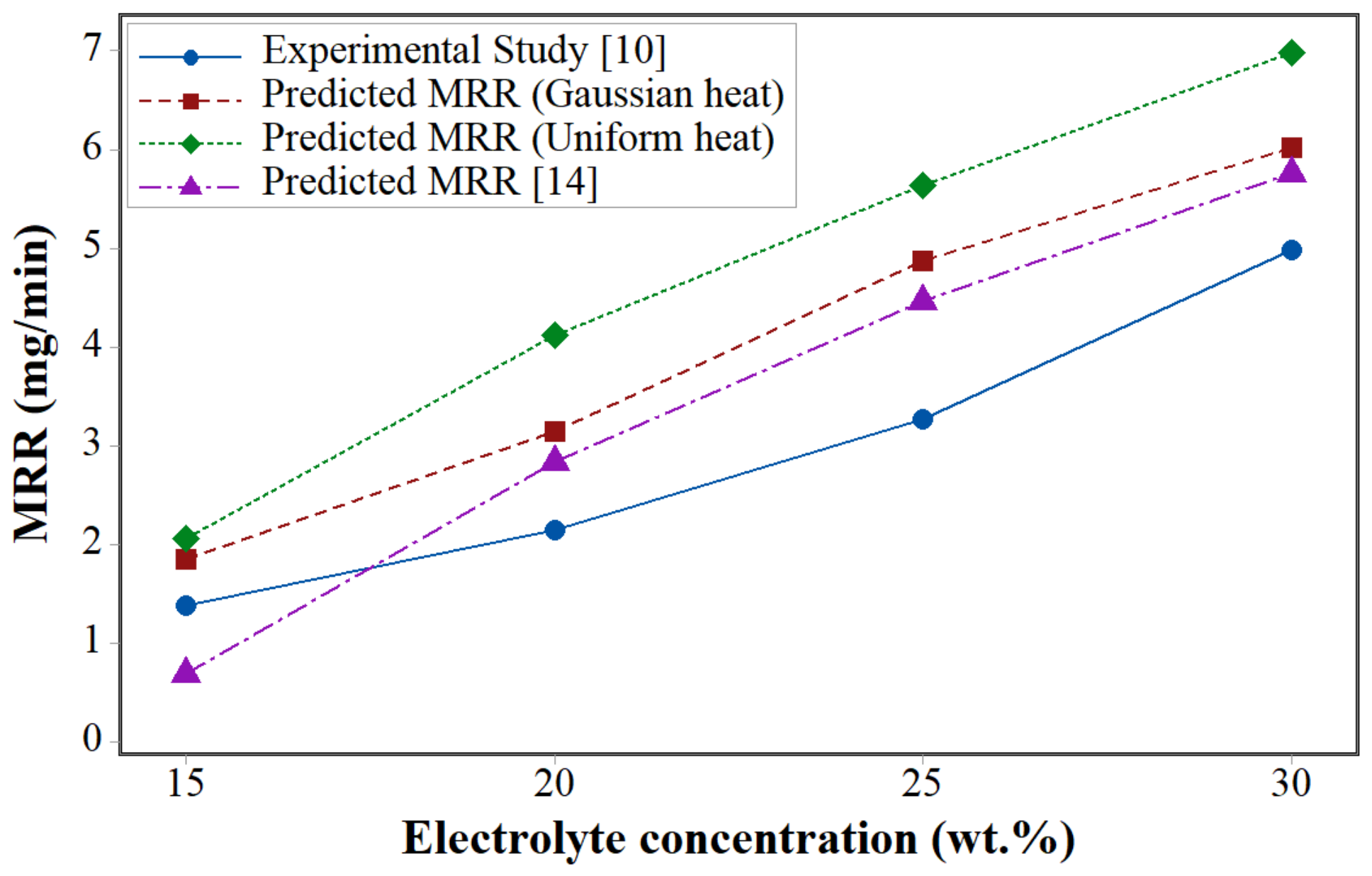

Figure 7

Comparison of MRR at different electrolyte concentration at $45 \mathrm{~V}$. 


\section{Temperature distribution}

Crater depth $\mathbf{v}$

\section{B: Transient Thermal}

Temperature

Type: Temperature

Unit: K

Time: $1 . e-004$ 2930.1

$2427,3 \quad 1924.4$

$275.98 \mathrm{Min}$

3181.6

\begin{tabular}{|l|l|l|l|}
\hline 3181.6 Max & 2678.7 & 2175.9 & 1673 \\
\hline & & & \\
\hline
\end{tabular}

(a)

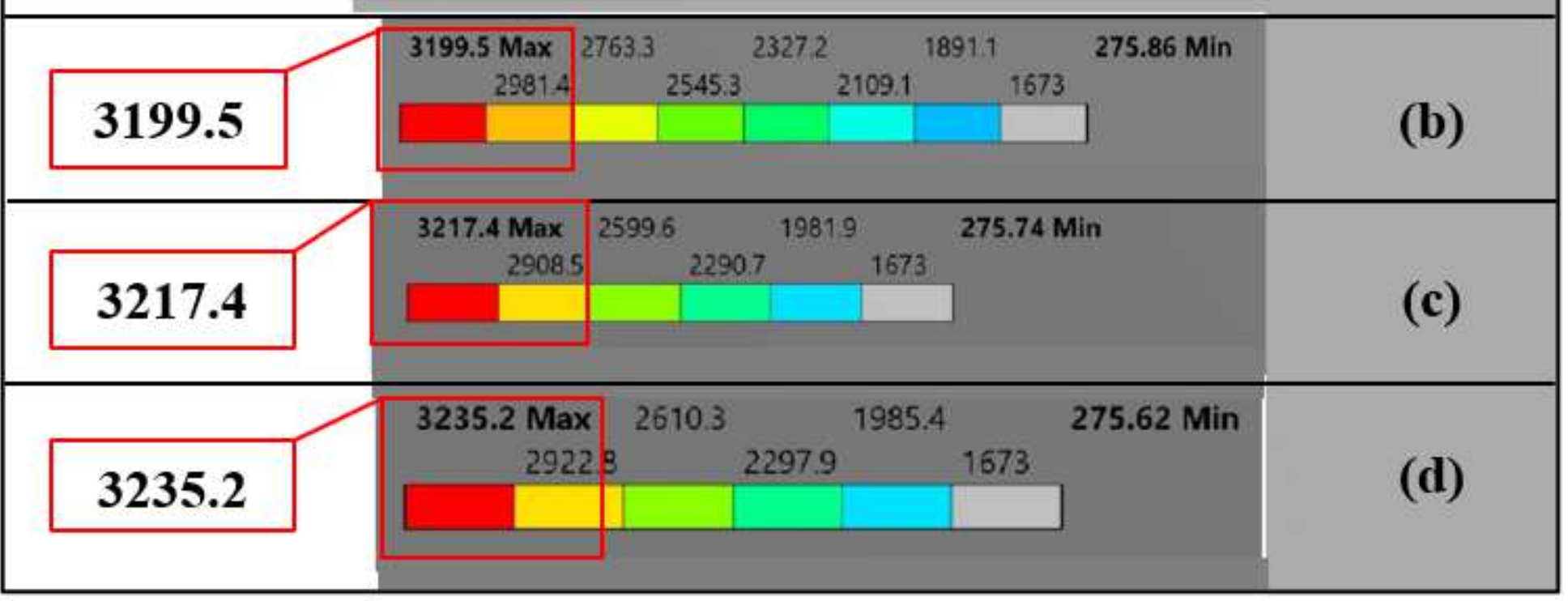

Figure 8

Work material temperature at different electrolyte concentration (a) 15 wt.\% (b) 20 wt.\% (c) 25 wt.\% (d) 30 wt.\%.

(a)

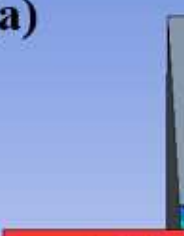

Imported Heat Flux

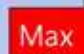

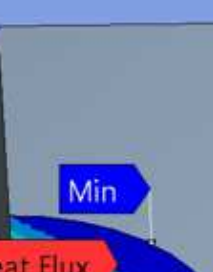

B: Transient Thermal Imported Heat Flux

Unit: $W / \mathrm{mm}^{2}$

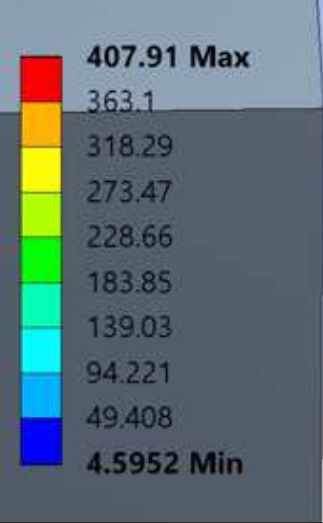

(b)

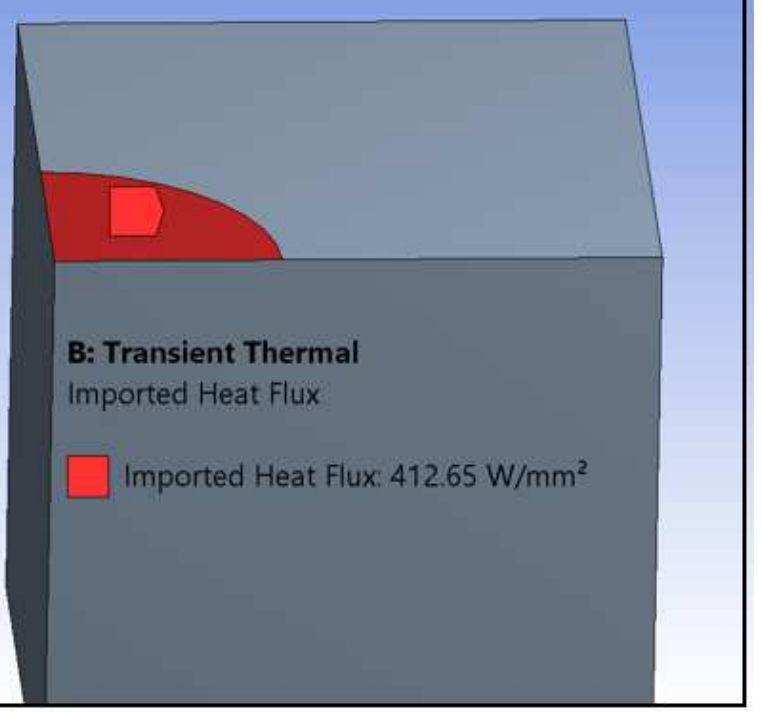


Figure 9

Heat input (a) Gaussian distribution (b) Uniform distribution.

(a)

Maximum over the spark region

B: Transient
Temperature

Type: Temperature

Unit: $\mathrm{K}$

Time: 1 e- 004

$13 \cdot 12 \cdot 202013.02$

$\begin{array}{llll}3340.7 \mathrm{Max} 2864.2 & 2387.7 & 1911.2 & 142.22 \\ \text { Min }\end{array}$

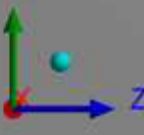

Work material

temperature

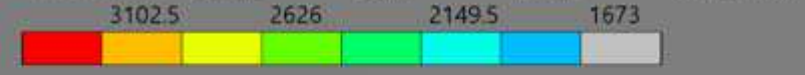

Max at the center

Decreases in a radial direction

(b)
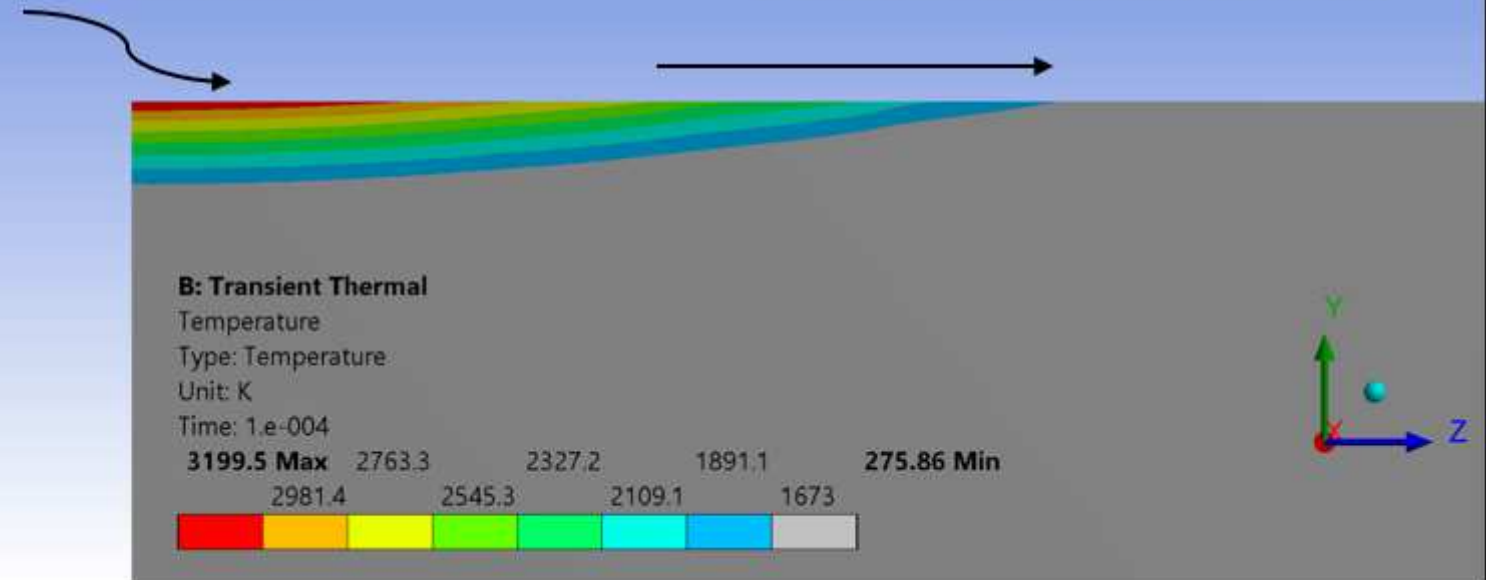

\section{Figure 10}

Crater shape (a) Uniform distribution (b) Gaussian distribution at $15 \mathrm{wt} . \% \mathrm{NaOH}$ and 45V. 


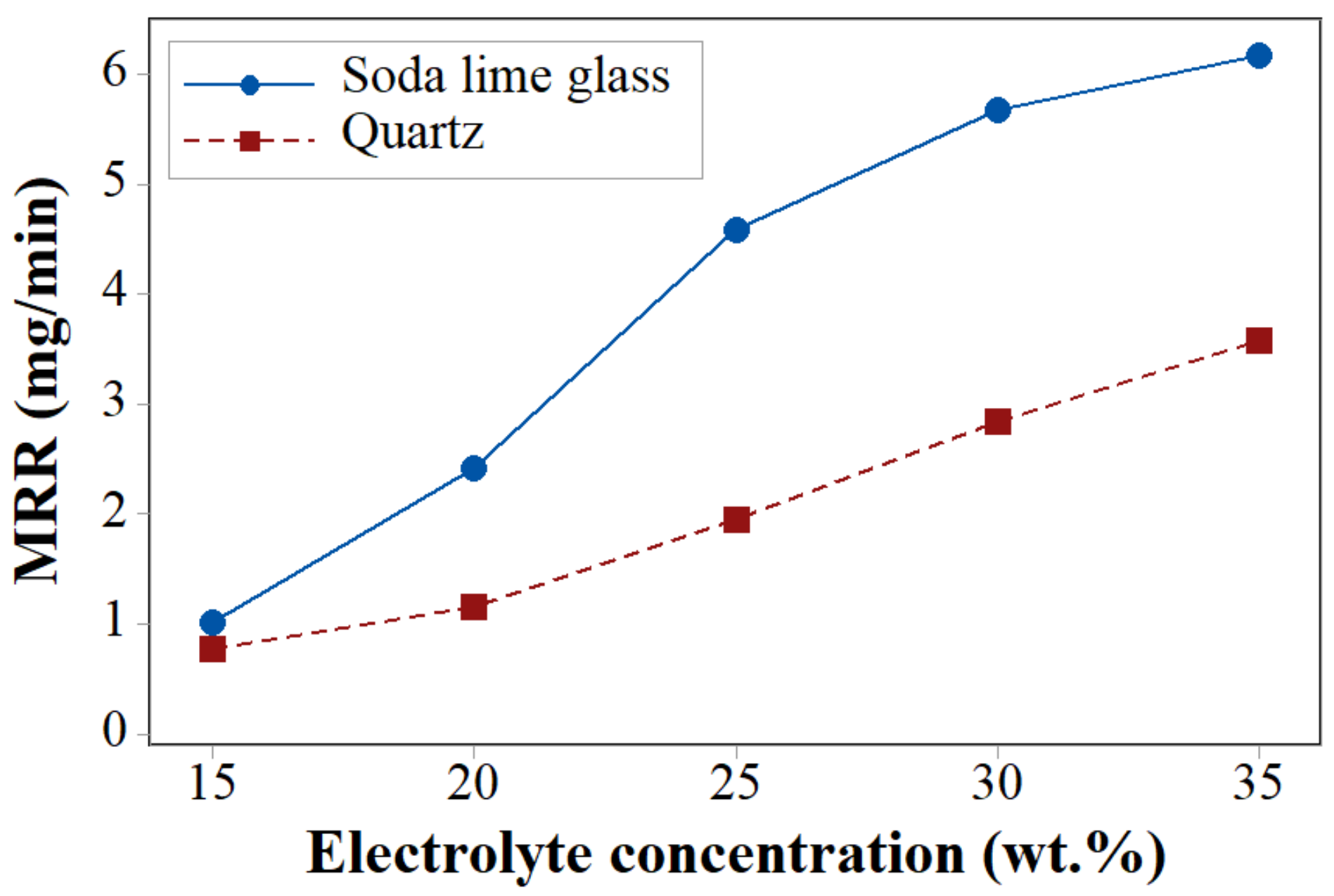

Figure 11

MRR comparison of different work materials at $45 \mathrm{~V}$. 


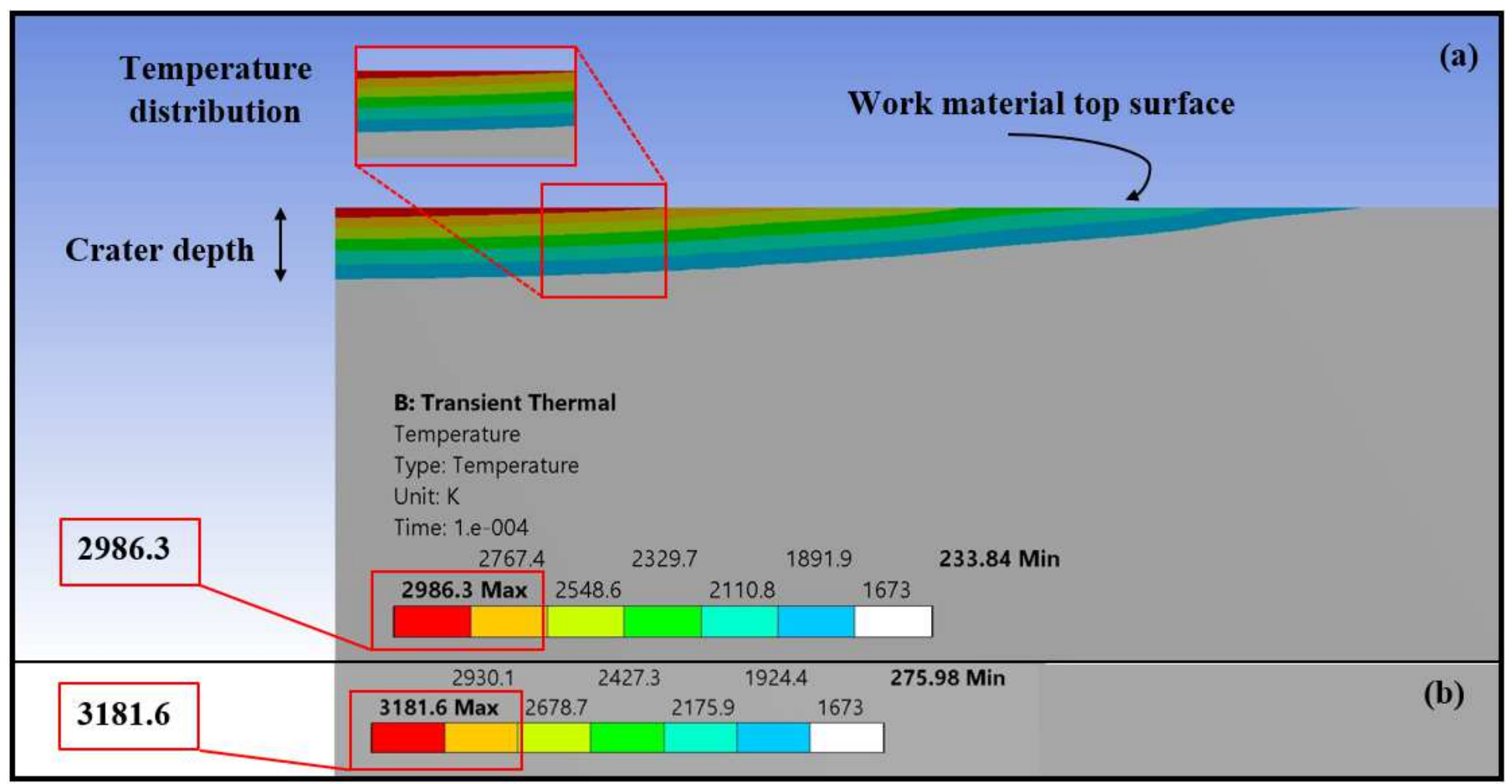

Figure 12

Work material temperature at $15 \mathrm{wt} . \%$ and $45 \mathrm{~V}$ (a) Quartz (b) Soda lime glass. 